\title{
Does river restoration result in improved environmental heterogeneity?
}

\author{
Junshuang $\mathrm{Yu}^{1, *}$ \\ ${ }^{1}$ University of Manchester, School of Environment, Education and Development, Manchester M13 \\ 9PL, United Kingdom
}

\begin{abstract}
Rivers can shape diverse landscapes, determine the spatial connectivity of river and terrestrial life, and provide a variety of resources and services. Rivers are often over-bound due to the need for flood control and irrigation. Rivers affected by human disturbance often require restoration to improve the ecosystem services they provide. Environmental heterogeneity is generally considered to be the non-uniform variation of environmental elements in space and/or time. The relationship between variability in physical characteristics of restored rivers and biological communities in the river environment is a highly complex feedback, and studying and summarising changes in environmental heterogeneity following river restoration can help refine methodologies for monitoring river restoration outcomes. This study highlights the variability in river geomorphology and river ecology, and demonstrates the feasibility and necessity of incorporating environmental heterogeneity indicators into river restoration outcome evaluation systems at three levels: hydrological, geomorphological and ecological.
\end{abstract}

\section{Introduction}

Environmental heterogeneity is generally manifested in the following aspects of the river environment: geomorphological units, river basin vegetation, sediment distribution and hydrological connectivity [1]. In contrast to heterogeneous natural systems, humans tend to homogenise the landscape, as is evident in agriculture, forestry and engineered waterways. However, there is a growing interest among restoration practitioners in incorporating forms of heterogeneity (e.g. micromorphological variability) observed in reference systems[2]. The homogenisation of physical habitats has been widely recognised as the greatest threat to river biodiversity and river ecosystem function, and the question of how to restore the heterogeneity of river environments has emerged as one of the key issues in the field of river restoration [3]. Most current river restoration projects are based on the assumption that restoring natural habitats leads to increased biodiversity [4]. However, the differences between natural habitats and river environments under human intervention have not been well studied. Do restored rivers exhibit more diverse environmental heterogeneity? How does environmental heterogeneity affect ecosystem restoration? These topics merit investigation.

*Corresponding author: yujunshuang@outlook.com 
Numerous river restoration projects have focussed on improving the hydrological morphology of rivers and their floodplains [5]. Subsequent ecological monitoring is usually limited to river quality assessments and rarely assesses riparian areas and floodplains. This approach has created a large gap in the monitoring of river restoration outcomes [6]. Additionally, multi-seasonal assessments are rarely employed. Our monitoring and assessment results may be subject to some error due to the variability of phenological characteristics.

River restoration practices often use conservative designs to create and maintain prescribed static forms. These approaches ignore the more recent understanding of resilient river systems, which often adjust their morphology in response to changes in hydrology, nutrients and sediment supply. Therefore, incorporating increased dynamics as a restoration design goal arguably yields a greater variety of productive habitats, better management expectations and more self-sustaining outcomes [7]. Habitat heterogeneity is a key factor in landscape, ecosystem and community processes across aquatic and terrestrial systems and is expected to have a significant impact on biodiversity and ecosystem function in restored systems. Further research is therefore necessary to understand the underlying causal relationships and to improve methods for incorporating appropriate heterogeneity into restoration[2].

This paper examines several cases of river restoration to both explore how environmental heterogeneity changes after river restoration and draw connections between changes in environmental heterogeneity and ecosystem restoration. This will help fill the methodological gap in the monitoring of river restoration outcomes.

\section{Physical morphological heterogeneity}

The hydrological morphology of rivers is primarily governed by factors intrinsic to the natural functioning of river systems (e.g., valley environment, catchment geology and climate) as well as by morphological conditions; these conditions further respond to changes in natural functioning (e.g., due to anthropogenic elements). It is furthermore important to note that the type of river also influences the potential for morphological change $[8,9]$. Belletti et al. assessed eight cases of river restoration in Europe using the Morphological Quality Index (MQI) and Monitoring Morphological Quality Index (MQIm) and compared the restoration extent with the adjacent downgraded extent (Table1.). A variety of restoration measures were taken, including removal of bank protection or artificial banks, river widening, and the reconnection or construction of secondary channels. Of these rivers, some host additional projects, such as the introduction of large timber or the reintroduction of sediment to raise the riverbed water level. Results suggested that the morphological condition of the degraded reaches were of poorer quality than the restored reaches. 
Table 1. Summary of MQI and MQIm values. Main changes in terms of broad categories of MQI and MQIm indicators before and after restoration are listed. 1, Aurino; 2, Becva; 3, Drau; 4, Lippe; 5,

Narew; 6, Thur; 7, Töss; 8, Vääräjoki (Belletti,2017).

\begin{tabular}{|c|c|c|c|c|c|c|}
\hline & $\begin{array}{c}\text { MQI } \\
\text { degraded }\end{array}$ & $\begin{array}{c}\text { MQI } \\
\text { before }\end{array}$ & $\begin{array}{l}\text { MQI } \\
\text { after }\end{array}$ & $\begin{array}{l}\text { MQIm } \\
\text { before }\end{array}$ & $\begin{array}{c}\text { MQIm } \\
\text { after }\end{array}$ & Changes (indicators) \\
\hline 1 & 0.59 & 0.54 & 0.73 & 0.67 & 0.79 & $\begin{array}{l}\text { Longitudinal continuity; bank } \\
\text { processes and lateral } \\
\text { continuity; channel and bed } \\
\text { morphology; vegetation } \\
\text { width and linear extent }\end{array}$ \\
\hline 2 & 0.34 & 0.34 & 0.58 & 0.46 & 0.7 & $\begin{array}{l}\text { Longitudinal continuity; bank } \\
\text { processes and lateral } \\
\text { continuity; channel and cross } \\
\text { section morphology; } \\
\text { vegetation width }\end{array}$ \\
\hline 3 & 0.5 & 0.55 & 0.75 & 0.69 & 0.82 & $\begin{array}{l}\text { Bank processes and lateral } \\
\text { continuity; channel and cross } \\
\text { section morphology }\end{array}$ \\
\hline 4 & 0.56 & 0.55 & 0.74 & 0.66 & 0.82 & $\begin{array}{l}\text { Lateral continuity; bed } \\
\text { morphology; vegetation } \\
\text { width and linear extent }\end{array}$ \\
\hline 5 & 0.64 & 0.7 & 0.7 & 0.76 & 0.76 & $\begin{array}{l}\text { Longitudinal continuity; } \\
\text { lateral continuity; vegetation } \\
\text { width }\end{array}$ \\
\hline 6 & 0.64 & 0.65 & 0.8 & 0.74 & 0.88 & $\begin{array}{l}\text { Bank processes and lateral } \\
\text { continuity; channel and cross } \\
\text { section morphology; } \\
\text { vegetation width }\end{array}$ \\
\hline 7 & l & 0.54 & 0.56 & 0.62 & 0.63 & $\begin{array}{l}\text { Lateral continuity; channel } \\
\text { morphology; vegetation } \\
\text { width }\end{array}$ \\
\hline 8 & 0.78 & 0.82 & 0.85 & 0.87 & 0.89 & $\begin{array}{l}\text { Channel and cross section } \\
\text { morphology }\end{array}$ \\
\hline
\end{tabular}

The above study suggests that river restoration can have a significant impact on river morphology. However, these study lacks an assessment of microhabitats and confirms only that river restoration has an impact on hydrological morphology at the macro level. In contrast, at a relatively micro level, and particularly on short time scales, microhabitat heterogeneity may be the first area of response following restoration [10], such as increased substrate heterogeneity and optimisation of hydrological connectivity.

Another study more specifically quantified the question 'Does post-restoration channel migration lead to increased in-channel geomorphic heterogeneity?' [7]. Morphodynamics were quantified and various geomorphic units systematically mapped by comparing pre- and post-restoration topographic maps within the Allt Lorgy area. The hypothesis was supported: river restoration enables more vigorous erosion of river banks and provides a more diverse range of sediments, allowing various geomorphological units to be created and enriching the environmental heterogeneity of the catchment. A $23 \%$ increase in the total area covered by 
geomorphic units within the river was observed after restoration, a significant increase in physical habitat resulting from river restoration. Additionally, the total area of 'bowls' and 'saddles' (geomorphic units) more than doubled between 2012 and 2016. The large increase in 'enclosures' was in turn due to the large number of steep erodible banks exposed following restoration, while the proportion of 'mounds' remained largely unchanged. The Shannon Diversity Index, which calculates geomorphic diversity, increased from 1.40 (2012) before restoration to 2.04 (2014) and 2.05 (2016) after restoration. This data suggests that the landscape pattern of the restored area is moving in the direction of greater heterogeneity.

Kondolf [11] argues that allowing rivers to develop freely by opening up migratory spaces can allow them to heal themselves to their full potential while also providing a more sustainable restoration effect. Ideas that give river space a morphological adjustment, such as river corridors and free space [12], have also received a great deal of attention in recent years. These theories bank on the idea that river migration creates and sustains greater heterogeneity in river environments, providing more diverse geomorphic units and physical habitat features [13].

Changes in river morphology are not solely caused by hydrodynamic features, however. In recent years, several new studies have provided scientists with a deeper understanding of the link between vegetation dynamics and river morphodynamics [14]. For example, how does vegetation modify water flow and sedimentation processes? And how do these processes in turn determine vegetation colonisation [15]? Through experiments and extensive field data, Nepf et al. [16] analysed how vegetation affects sediment transport in rivers. In stream restoration, aquatic and riparian vegetation can reduce local flow rates to reduce soil transport and streambank erosion while also increasing sediment accumulation [17]. Plant root action can also increase local streambank stability [18]. These factors are crucial in river morphodynamics, especially after a river has undergone river restoration. When vegetation appears as a non-homogeneous factor in morphodynamic models, more unpredictable heterogeneous changes are expected. The vegetation factor is still treated quite simplistically in the morphological models currently under consideration [19]. Furthermore, the relationship between seasonal changes in vegetation and seasonal flooding is often overlooked.

\section{River restoration and ecology}

To determine if a greater proportion of heterogeneous geomorphic units would also be accompanied by improved ecosystems, it is necessary to assume that restoration-based changes are associated with changes in natural habitats. After river restoration work is completed, staff often limit follow-up activity to water quality assessments and rarely bother with long-term ecological monitoring. Furthermore, monitoring typically focusses on the body of water itself, with limited assessment of the heterogeneity of the nearby floodplain and riparian environment.

A review by Corenblit et al. [11] describes the interdependence between abiotic processes and biotic responses, highlighting the important correlation between river disturbance and riparian vegetation and suggesting that riparian vegetation is an important factor when evaluating river restoration outcomes. Researchers studying changes in riparian vegetation cover heterogeneity usually need to make the following assumptions: first, floodplain expansion will be accompanied by an increase in habitat heterogeneity, which usually includes such factors as habitat size, quality and diversity. Second, species composition and preferences will respond to the functional integrity of the ecosystem as a habitat. 

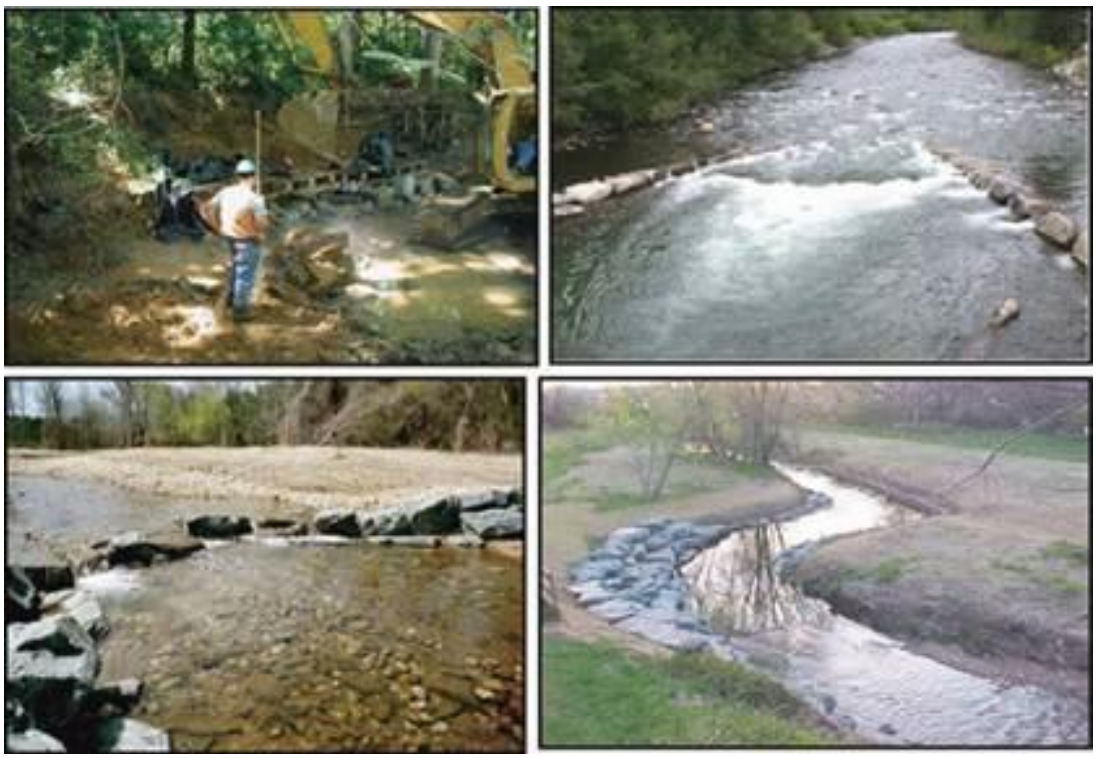

Fig. 1. River restoration projects are undertaken to enhance habitat heterogeneity. Top left: Large equipment often used to reconfigure and create artificial pools and habitat structures. Top right: Rocks placed in the channel can deflect flow to increase variable habitat. Bottom right: Artificial meanders created by reconfiguring the channel. Bottom left: Inflow rock structures can create shallow pools downstream [1].

Modrak et al. [5] evaluated the riparian vegetation of 43 river restoration projects (conducted between 1987 and 2008) on 28 rivers in western Germany and selected sites where significant river morphological restoration had taken place [20]. Seventy-two percent of these projects were located in mountainous areas while the rest were located in valleys, and up to $37 \%$ of the included floodplains were associated with mountainous rivers. Most of these rivers are highly dynamic and appear to be very active in terms of morphological shaping. Restoration measures have significantly improved the morphology of these river basins, with a $37 \%$ reduction in section category and a $28 \%$ reduction in profile depth within the floodplain. Islands of vegetation began to appear in moderately stable profiles after restoration, a change presumably due to the increased morphological diversity caused by the widening of the riverbed. A total of 456 plant species were recorded from the 792 sampling sites in the restored area, compared to only 313 species in the unrestored portion. Although the restored area displayed a larger species pool, there is no denying that the similarity between the two species pools is extremely high. In the restored section, the additional species showed a tendency to tolerate both dry and wet conditions, particularly along the river where species have shifted to wet preference types; this change in species composition heterogeneity was most evident in the large lowland rivers. In contrast, species in restored areas favoured high nutrient conditions, with the mountains showing lower heterogeneity than the lowlands. The above study confirms our hypothesis that restored rivers will display greater habitat heterogeneity and allow for a more diverse species assemblage and higher biodiversity.

Not only is riparian restoration effective, but restoration measures that do not explicitly target lower riparian areas continue to have a positive impact on the riparian vegetation regime. For example, the removal of bank fixtures often results in the inundation of shallow banks. In a study conducted by Bornette [13], plant species identified tolerance and showed this regular flooding in terms of preference, leading to detectable differences in ecological preferences across the plant community. These results suggest that changes in vegetation 
heterogeneity following restoration can potentially act as indicators of ecological function in restored river floodplains.

Vegetation is sensitive to increased habitat heterogeneity following river restoration; however, not every organism responds perceptibly to changes in environmental heterogeneity. Benthic invertebrates are the most common biota used in river biomonitoring [21], while crustaceans (Crustacea) indicate the strength of water-land interactions [22]. While comparing habitat assemblages and composition before and after river restoration by cluster analysis, Jähnig et al. (2009) found that for benthic invertebrates, aggregation did not change significantly before and after restoration. Additionally, ground beetle assemblages responded strongly to the heterogeneity brought about by restoration, though this response was not as strong as that of vegetation [23]. It is worth noting that although the river increased in species richness after restoration, the change in species diversity was not significant. The increase in ground beetles was closely related to improved gravel conditions but not strongly associated with vegetation cover. The increase in benthic populations was due to the optimisation of hydrological patterns, which resulted in more diverse and available microhabitats, but this does not imply that some sensitive taxa will move in. While river restoration can increase habitat heterogeneity, the new habitats generated often do not have high-quality environmental conditions and do not necessarily attract the settlement of sensitive species immediately following restoration [23].

Although fish are among the best known aquatic organisms, it is difficult to measure the response of fish to the environmental diversity of restored rivers, and little literature on the subject exists. It has been observed, however, that river width affects the ecological response of restored rivers, and previous research has demonstrated that the response of fish abundance to increased post-restoration environmental heterogeneity is more pronounced in larger, wider rivers. For example, salmon abundance in rivers greater than $8 \mathrm{~m}$ in width can be significantly affected by river restoration efforts [24]. Manfrin et al. (2019) studied 134 restoration projects implemented in 77 rivers across Europe and found that fish life histories can be altered by river restoration, changes that are closely linked to changes in the physical environment of the river following restoration. After restoration, the characteristics of the population's opportunistic strategy decreased by $9 \%$ within the restoration reach. This further suggests that changes in the life histories or trait compositions of organisms are helpful in understanding secondary successional processes in restored reaches.

\section{Conclusion and discussion}

Although many cases of river restoration exist, there is little ongoing monitoring of the morphology and ecology of restored rivers. Restored rivers involve three levels of variability - hydrology, geomorphology and ecology - which usually interact at different spatial scales. For example, hydrology and hydrodynamics dominate variability in river geomorphology, while variability in geomorphic units increases habitat diversity, which can in turn affect species richness and diversity. Changes in ecosystem function following restoration can also influence the geomorphic and hydrological characteristics of the river; for example, richer vegetation colonisation reinforces river banks and an increase in aquatic plants affects the control of flow velocity [25]. In these three links, changes in heterogeneity act in tandem. In the restored river, the spatial extent of in-channel geomorphology is greatly enhanced and a diverse mix of geomorphic units is created, fully reflecting the response of environmental heterogeneity to the restoration project. In turn, changes in heterogeneity at the ecological level also emerge in response to variability in the physical environment. The interaction between vegetation and hydrogeomorphology in river systems is detailed in a review by Solari [9], who present relevant models. Gurnell and Grabowski (2016) also consider the different roles of fluvial vegetation on the changing heterogeneity of geomorphic units in 
gravelly riverbeds. Finally, Wolter [26] review how fish communities respond to changes in environmental heterogeneity, which relates to changes in diverse habitat requirements and life history traits.

Historically, researchers have treated the individual sections and components of a river as separate entities, working empirically and employing engineering concepts of restoration. Now, there is a growing body of research that demonstrates that the river represents a whole but heterogeneous entity, with hydrology, geomorphology and ecology together forming a dynamic and heterogeneous assemblage. In the restoration of rivers, greater consideration should be given to the interaction of these three dimensions and the spatial scales they encompass. The three levels of heterogeneity should be nested according to the characteristics of each restored river [27] and used to develop a rational river restoration plan. The development of environmental heterogeneity should be proactively planned and designed for rather than passively accepted.

It is equally important to monitor changes in ecological function following river restoration. Past assessment tools have been primarily limited to short- to medium-term water quality monitoring, which goes against the principle of the holistic nature of rivers. Using existing tools such as geomorphological classification [7] and remote sensing, it is possible to incorporate indicators of environmental heterogeneity into the evaluation of river restoration outcomes. Standardising the evaluation of ecological components such as vegetation, fish and invertebrates and establishing a standardised evaluation system that focusses on 'hydrological, geomorphological and ecological' variability will be key priorities for future river restoration work.

\section{References}

1. M.A. Palmer, H.L. Menninger, E. Bernhardt, Freshwater Biology 55, 205-22 (2010)

2. D.J. Larkin, G.L. Bruland, J.B. Zedler, Foundations of Restoration Ecology, 271-300 (2016)

3. W. Gostner, M. Alp, A.J. Schleiss, C.T. Robinson, Hydrobiologia 712(1), 43-60 (2012)

4. S.W. Miller, P. Budy, J.C. Schmidt, Restoration Ecology 18(1), 8-19 (2010)

5. P. Modrak, S. Brunzel, A.W. Lorenz, Ecohydrology 10(5) (2017)

6. B. Belletti, L. Nardi, M. Rinaldi et al., Environ Manage 61(1), 69-84 (2018)

7. R.D. Williams, S. Bangen, E. Gillies et al., Sci Total Environ. 715, 136817 (2020)

8. A.M. Gurnell, R.C. Grabowski, River Research and Applications 32(2), 202-15 (2016)

9. L. Solari, M. Van Oorschot, B. Belletti et al., River Research and Applications 32(2), 164-78 (2016)

10. K. Januschke, S.C. Jähnig, A.W. Lorenz, D. Hering, Ecological Indicators 38, 243-55 (2014)

11. D. Corenblit, A.C.W. Baas, G. Bornette et al., Earth-Science Reviews 106(3-4), 307-31 (2011)

12. P.M. Biron, T. Buffin-Belanger, M. Larocque et al., Environ Manage 54(5), 1056-73 (2014)

13. G. Bornette, E. Tabacchi, C. Hupp et al., Freshwater Biology 53(8), 1692-705 (2008)

14. A. Vargas-Luna, A. Crosato, N. Anders et al., Earth Surface Processes and Landforms 43(8), 1591-607 (2018)

15. A. Gurnell, Earth Surface Processes and Landforms 39(1), 4-25 (2014)

16. H.M. Nepf, Annual Review of Fluid Mechanics 44(1), 123-42 (2012) 
17. S.D. Keesstra, E. Kondrlova, A. Czajka et al., Netherlands Journal of Geosciences Geologie en Mijnbouw 91(1-2), 245-55 (2014)

18. F. Berendse, J. van Ruijven, E. Jongejans et al., Ecosystems 18(5), 881-8 (2015)

19. J.A. Cotton, G. Wharton, J.A.B. Bass et al., Geomorphology 77(3-4), 320-34 (2006)

20. P. Haase, D. Hering, S.C. Jähnig et al., Hydrobiologia 704(1), 475-88 (2012)

21. D. Hering, R.K. Johnson, S. Kramm et al., Freshwater Biology 51(9), 1757-85 (2006)

22. A. Paetzold, C. Yoshimura, K. Tockner, Journal of Applied Ecology 45(3), 894-903 (2007)

23. S.C. Jähnig, A.W. Lorenz, D. Hering, Aquatic Conservation: Marine and Freshwater Ecosystems 19(2), 157-69 (2009)

24. J. Kail, K. Brabec, M. Poppe, K. Januschke, Ecological Indicators 58, 311-21 (2015)

25. R.C. Grabowski, AM. Gurnell, River Research and Applications 32(2), 139-41 (2016)

26. C. Wolter, A.D. Buijse, P. Parasiewicz, River Research and Applications 32(2), 190-201 (2016)

27. L.E. Polvi, L. Lind, H. Persson et al., J. Environ Manage 265, 110288 (2020) 